\title{
IDENTIFICATION OF TREATED-COLOR FRESHWATER CULTURED PEARLS
}

\section{Karampelas S. ${ }^{1,2}$, Fritsch E. ${ }^{2}$, Sklavounos S. $^{1}$, and Soldatos T. ${ }^{1}$}

${ }^{1}$ Department of Geology, Laboratory of Mineralogy - Petrology - Economic Geology, Aristotle University of Thessaloniki, 54124 Thessaloniki, Greece (corresponding author: steka@physics.auth.gr)

${ }^{2}$ Université de Nantes, Nantes Atlantique Universités, CNRS, Institut des Matériaux Jean Rouxel (IMN), Laboratoire de Physique des Matériaux et Nanostructures- 2 rue de la Houssiniere, UMR6502,BP32229, F-44322 Nantes Cedex 3,France

\begin{abstract}
Demand for colored pearls has grown during the last thirty years. Colored pearls are rarer than white ones. Thus treated-color pearls have entered the marketplace and their identification became a challenge for the gemologists. With only the help of visual observation, EDXRF and X-radiography, methods that are used today for pearls identification, it is not always easy to identify them. Previous studies, have established that Raman scattering is useful to detect pigments in cultured freshwater pearls. The present study is based on the measurement of the Raman spectroscopy of 35 natural colored freshwater pearls and 15 treated-color freshwater pearls, covering a wide range of typical colors for this material, with green excitation. All natural-color pearls show the two major Raman resonance features of polacetyenic pigments assigned to $C=C$ stretching-at about $1530( \pm 25) \mathrm{cm}^{-1}$ - and $C-C$ stretching at about $1130( \pm 10) \mathrm{cm}^{-1}$-, regardless of their specific hue. In this paper it is proposed that the absence of these Raman features prove the artificial origin of pigments in a colored freshwater cultured pearl.

Key words: Raman spectroscopy, polyacetylenic pigments, Hyriopsis mollusk.
\end{abstract}

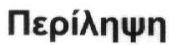

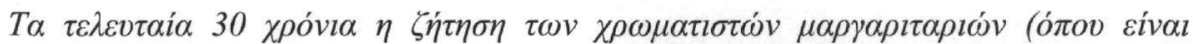

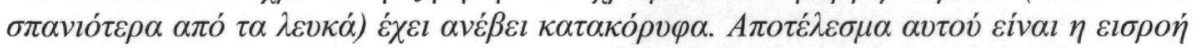

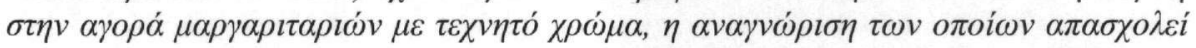

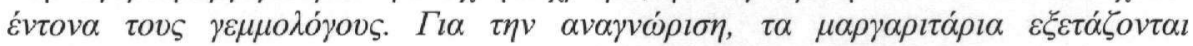

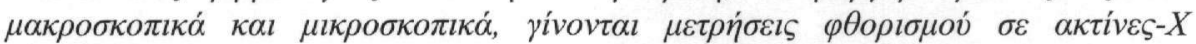

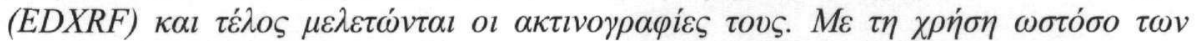

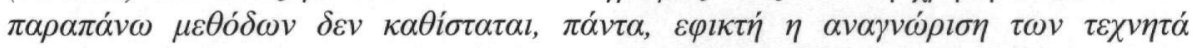

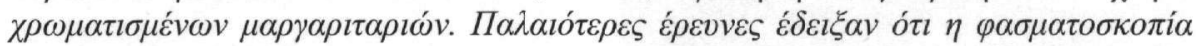

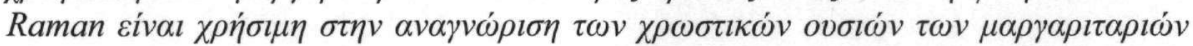

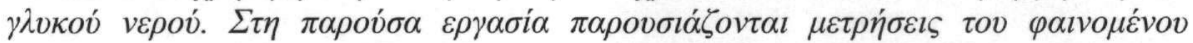

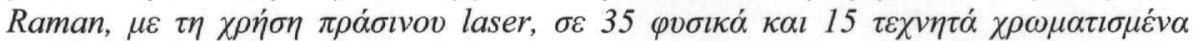

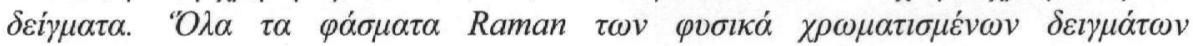




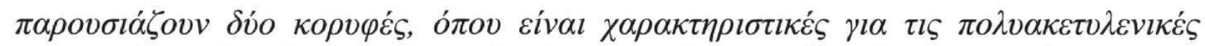

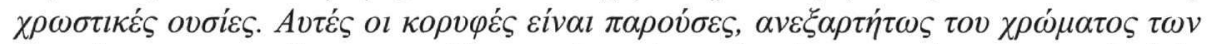

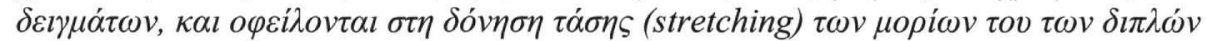

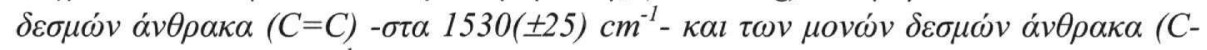

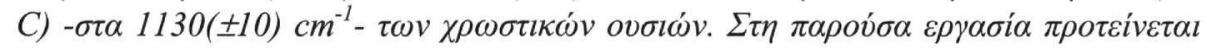

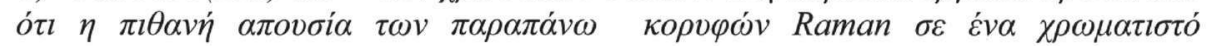

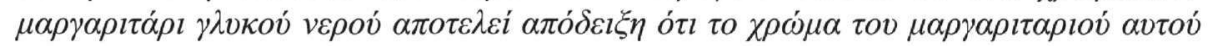

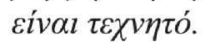

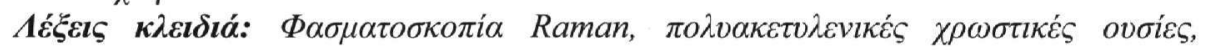

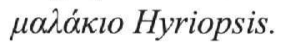

\section{Introduction}

Pearl is unique amongst gem materials in that, apart from being drilled, it is mostly worn as it is found; whereas, with the exception of the rare well-formed crystal, diamonds, rubies, sapphires and emeralds all require cutting and polishing before they are seen at their best. Perhaps because of this there are one of the oldest gems known to man. Pearl is also unusual as a gem material in that is growing today in many different parts of the world (China, Japan, Korea, Vietnam, Red Sea, Australia, New Zealand, Indonesia, Tahiti, Philippines, North and South America, Caribbean, Scotland,) (Jobbins et al. 1990, Schoeffel 1996, Komatsu 1999).

The vast majority of references found for pearls through the ages concern white pearls. From the 1980 s, on the gem market have seen an explosion of interest for colored pearls (Sweaney 1984, Goebel et al. 1989, Li et al. 2001, Elen 2001). The colored pearls are rarer than their white counterparts, thus they are more expensive. As demand of this material has grown, treated-color pearls have also entered the marketplace. Treated pearls should be prized normally at a lesser value than the natural-color ones but they are often sold at the same price. This happens because the separation of natural from treated-color pearls is sometimes difficult. As a consequence, there has been a diminution of buyers' confidence and natural-color cultured pearls price.

For this work we are particularly interested in the separation of natural-color freshwater cultured pearls from their treated-color equivalents. For this purpose we are using Raman scattering.

\section{Background}

Pearl is a calcareous body, composed of concentric layers around a central nucleus, organically produced by a living mollusk (phylum Mollusca). Calcareous bodies are found in the majority of the mollusks, which have a calcareous shell. However, not all pearls are desirable but a few species of mollusks have the particularity to produce iridescent calcareous bodies (Hänni 1999). Pearls are known to come mainly from some marine gastropods, marine and freshwater bivalves.

A natural pearl is a natural concretion secreted accidentally, in a mollusk, without any human intervention. Depending the growth environment, natural pearls are separated into freshwater and saltwater varieties. Natural pearl formation has for a long time depended largely on 'legends' related to irritating intrusions or intruders (e.g. sand grain or parasite). Nowadays, it can be said that natural pearls are produced because of a deregulation during shell's formation. The exact causes of these deregulations are not known yet, in detail.

Cultured pearls are created in mollusks after human intervention. Depending on their growth environment, they are separated in freshwater and saltwater cultured pearls. We can divide them also, depending on their nucleus, into non-nucleated (transplantation just of a tissue) cultured pearls and bead-nucleated pearls (tissue transplantation with simultaneous bead implantation). The majority of cultured freshwater pearls are tissue-nucleated (mainly from China) and the vast majority of cultured saltwater pearls are bead-nucleated (Goebel et al. 1989, Scarratt et al. 2000, Akamatsu et al. 2001). 
Searching the bibliography, one notes that only a few mollusks species are used for commercial cultivation. For saltwater cultured pearls (SWCP) these are the bivalves Pinctada margaritifera commercially called Tahitian cultured pearls-, Pinctada fucata (martensii) -commercially called Akoya cultured pearls-, Pinctada maxima -commercially called South Sea cultured pearls-, Pteria sterna, and more rarely the univalve Haliotis iris -commercially called rainbow abalone pearls-. For freshwater pearls, the following bivalves are used for cultivation: Hyriopsis schlegelii (H. schlegelii) -commercially called Biwa cultured pearls-, Hyriopsis cumingii ( $\mathrm{H}$. cumingii) commercially called Chinese freshwater cultured pearls- and the hybrid Hyriopsis schlegeliixcumingii -commercially called Kasumigaura freshwater cultured pearls-.

The last 20 years, on the gem market have seen an explosion of interest for colored pearls. Freshwater cultured pearls (FWCP) occur in four main hues -white, grey, orange and purple-. However various combinations of tone and saturation yield a broad range of color appearances. Over the last few years colored pearls demand has increased significantly, thus treated-color pearls have also entered the marketplace in large numbers.

Pearl color treatments fall into two categories: those prior to drilling and after drilling. The most common dye is silver salts (i.e. silver nitrate, silver chloride etc) to turn the pearls color darker. Iodine is used also to turn pearls color into yellow (Elen 2001). Various organic dyes are also used for pearls color treatment, in order to obtain a variety of colors. Between them carotene for the dyed golden pearls and for the black ones are known (Li et al. 2001). Dyes and chemicals typically are used after drilling, to facilitate their entry parallel to the nacre layers (Elen 2001) but predrilling can be used also (Gauthier et al. 1990). More recent treatments used for pearls is irradiation -i.e. after exposure to $\gamma$-rays the pearls turn grey, bluish grey and black- (Matsuda et al. 1988, Goebel et al. 1989, Fengming et al. 2003) and heat treatment -to turn the pearls color yellowish - (Vock 1997, Elen 2001). Both of the treatments above may be performed pre and postdrilling.

The challenge for the gem and jewelry industry is to separate natural-color cultured pearls, of any color, from treated ones. The main method used for detecting pearl color treatment is visual observation (at different magnifications, from unaided eye to microscope in reflective light). An unusual color concentration can be detected in the form of a colored layer (visible in the drill hole, if the pearl is drilled) or a color spot or streak visible on the surface (Hurwit 1984, Goebel et al. 1989, Hargett 1989, Crowningshield 1991, Kennedy 1998, Elen 2001). These areas are often more porous (as indicated by a cloudy or milky appearance prior to treatment), which allows the dye or chemical to became concentrated (Elen 2001). The relatively saturated color at the surface of the nacre, which became lighter as one looked deeper into the drill hole, suggests that the pearls exhibiting this feature were color treated prior to drilling (Elen 2002). Had color treatment been applied after drilling, it most likely would appear to color the nacre uniformly within the drill hole, or to be concentrated at the conchiolin layer between the nucleus and the nacre (Gauthier et al. 1990, Elen 2002). However, undrilled pearls - especially in the absence of obvious visual featuresare much more difficult to identify (Elen 2001). Moreover, colored FWCPs do not present any luminescence under short-wave and long-wave UV radiation, thus this method is useless, except if the nacre is rich of any "suspicious" pigment which generally suppresses the luminescence.

EDXRF (Energy Dispersive X-ray Fluorescence) is a method traditionally used for the separation of saltwater from freshwater pearls. The separation is based on the fact that freshwater pearls contain an elevated concentration of manganese compared to saltwater pearls (Kane 1990, Gütmannsbauer et al. 1994, Kennedy 1998). EDXRF is also used for detecting the presence of inorganic treatments such us silver salts, iodine, bromine etc (Goebel et al. 1989, Elen 2001). However, this method is useless for the detection of organic dyes, detection of inorganic dyes contained elements lighter than boron irradiated and heat-treated pearls.

Radiography (X-ray shadowgraph) is a method traditionally used for the identification of natural and cultured pearls as well as of bead-nucleated and tissue-nucleated pearls (Fryer 1984, Kennedy 
1998, Scarratt et al. 2000, Akamatsu et al. 2001). Moreover, this method is used to detect silver nitrate dye. Metallic silver (deposited from the silver nitrate solution) is opaque to X-rays, this area commonly appears white on the X-radiograph (Hargett 1987, Goebel et al. 1989). However, only this color treatment can be detected by radiography.

Finally, Raman scattering is used to detect natural pigments on pearls and in some cases to detect color treatments. All the pearls present the characteristic peaks of aragonite at $702 \mathrm{~cm}^{-1}$ (normally a doublet at 701 and $705 \mathrm{~cm}^{-1}$ depending on the resolution used) and $1085 \mathrm{~cm}^{-1}$. Colored FWCPs peaks at around $1130( \pm 10) \mathrm{cm}^{-1}$ and $1530( \pm 25) \mathrm{cm}^{-1}$, which are characteristic of polyenic pigments. Recent studies have been shown that FWCP's natural colors are due to a mixture of polyacetylenic pigments. The same pearl can contained up to 9 different pigments of general chemical formula $\mathrm{R}-(-\mathrm{CH}=\mathrm{CH}-)_{\mathrm{N}}-\mathrm{R}$, with $\mathrm{N}=6$ to 14 (where $\mathrm{N}$ is the number of carbon double bonds in the polyenic chain, $\mathrm{R}$ and $\mathrm{R}$ ' the end groups of pigments chemical formula which are still unknown). Different mixtures explain different colors, not a simple change of pigment (Karampelas et al. 2007). Some dark colored dyed with organic substances show peaks at around 1340 and $1598 \mathrm{~cm}^{-1}$-caused by an unknown organic dye- and silver nitrate dyed pearls may not show the typical peaks of aragonite, but only broad peaks at 1571,1594 and $2918 \mathrm{~cm}^{-1}$-may because of degradation of pearls organic matrix during the treatment- (Li et al. 2001). It is cited that silver nitrate treatment can be identified also because it produces a band at $240 \mathrm{~cm}^{-1}$ (Kiefert et al. 2004).

\section{Materials and Methods}

The present study is based on the measurement of the Raman scattering of 35 natural-color (including 3 white) FWCPs (Table 1) and 15 treated-color FWCPs (Table 2), covering a wide range of typical colors for this material. The samples are borrowed from reputed commercial sources (see acknowledgements). Raman scattering spectra were obtained on a Jobin Yvon T64000 spectrometer coupled to an Olympus metallurgical microscope (BHSM) at the IMN (Institut des Matériaux Jean Rouxel, France). We used $514.53 \mathrm{~nm}$ (green) as excitation wavelength emitted by an ionized argon laser, using the spectrometer's microscope (magnification of 50x) and a camera for adequate positioning of the beam. Measured areas were about $2 \times 2 \mu \mathrm{m}$. For pearls with inhomogeneous color distribution (see Tables 1,2), spectra were taken in areas of different color. Backscattered light was dispersed on a 1800 grooves $/ \mathrm{mm}$ holographic grating. Low laser powers $(2 \mathrm{~mW})$ and short acquisition times (20 seconds) were used in order to avoid any destruction of fragile organic matter. Rayleigh scattering of the excitations was blocked by a holographic notch filter. For all measurements slits were set at $40 \mu \mathrm{m}$, including a resolution of 1 $\mathrm{cm}^{-1}$.

\section{Results}

The Raman spectra of different colored pearls in the $600-1600 \mathrm{~cm}^{-1}$ range are presented in figures 1-6. Note that all spectra are normalized to the major Raman peak of aragonite (at $1085 \mathrm{~cm}^{-1}$ ), which is by far the major constituent of the pearls. It can therefore be considered as an internal standard. This allows a better comparison concerning the relative intensity of the pigments signals. All spectra are stacked and shifted for clarity.

In figure 1, Raman spectra of a white and of a grey colored freshwater pearl. For the white sample we observed the band at about $1085 \mathrm{~cm}^{-1}$ and the doublet at about 702 and $706 \mathrm{~cm}^{-1}$ which correspond respectively to the $v_{1}$ symmetric and the $v_{4}$ in-plane bending mode of the carbonate ion $\left(\mathrm{CO}_{3}{ }^{2-}\right)$ in aragonite. Strong luminescence in the green region is noted but no additional peaks linked to pearl are observable. Since this spectrum is obtained on a white pearl, it establishes a 'blank' spectrum for spectra of pearls from the same mollusk. The spectra of the grey colored FWCPs present two intense additional bands in the $1000-1600 \mathrm{~cm}^{-1}$ region. These are characteristic of polyenic chains (Salares et al. 1977). Two features are due polyenic chains, the 
$\mathrm{C}=\mathrm{C}$ stretching $\left(v_{1}\right.$ near1500 $\left.\mathrm{cm}^{-1}\right)$ and $\mathrm{C}-\mathrm{C}$ stretching $\left(v_{2}\right.$ near $\left.1130 \mathrm{~cm}^{-1}\right)$ (Salares et al. 1977). The characteristic polyene lines are not observed in the spectra of white pearls (Fig. 1). These lines are clearly found in all untreated-color freshwater cultured pearls examined for this study, regardless of their specific hue, and show unambiguously that a similar conjugated double bond system is responsible for their pigmentation.

Table 1 - Description of our samples of natural colored cultured freshwater pearls describing their color range and homogeneity

\begin{tabular}{|c|c|}
\hline Sample number/Mollusk & Color description and distribution \\
\hline SK06/H.cumingii & orange (homogeneous) \\
\hline SK07/H.cumingii & grey-light violet (homogeneous) \\
\hline SK08/H.cumingii & grey zoned pinkish/more grey (inhomogeneous) \\
\hline SK09/H.cumingii & orange (homogeneous) \\
\hline SK10/H.cumingii & grey/more grey(inhomogeneous) \\
\hline SK29/H.cumingii & pink-grey ' clear pink' (homogeneous) \\
\hline SK30/H.cumingii & orange -slight grey-(homogeneous) \\
\hline SK31/H.cumingii & pink-grey' clear pink' (homogeneous) \\
\hline SK32/H.cumingii & violet-grey (homogeneous) \\
\hline SK33/H.cumingii & pink-grey 'clear pink' (homogeneous) \\
\hline SK37/H.cumingii & pink-orange / orange-pink (inhomogeneous) \\
\hline SK56/H.cumingii & white-cream (homogeneous) \\
\hline SK57/H.cumingii & white-cream (homogeneous) \\
\hline SK58/H.cumingii & orange -slight grey-(homogeneous) \\
\hline SK59/H.cumingii & orange -slight grey-(homogeneous) \\
\hline SK60/H.cumingii & pink-grey ' clear pink' (homogenous) \\
\hline SK61/H.cumingii & pink-grey ' clear pink' (homogeneous) \\
\hline SK83/H.cumingii & Orange up/middle/down (inhomogeneous) \\
\hline SK84/H.cumingii & violet-grey up/middle/down (inhomogeneous) \\
\hline SK85/H.cumingii & grey -little violet- up/middle/down (inhomogeneous) \\
\hline SK86/H.cumingii & pink-grey 'clear pink' up/middle/down (inhomogeneous) \\
\hline SK87/H.cumingii & little violet-little grey up/middle/down (inhomogeneous) \\
\hline SK88/H.cumingii & violet-grey up/middle/down (inhomogeneous) \\
\hline SK89/H.cumingii & violet-grey (homogeneous) \\
\hline SK90/H.cumingii & violet-grey (homogeneous) \\
\hline SK91/H.cumingii & grey (homogeneous) \\
\hline SK92/H.cumingii & grey (homogeneous) \\
\hline SK104/H.cumingii & violet pinkish/greenish (inhomogeneous) \\
\hline SK105/H.cumingii & violet pinkish/greenish (inhomogeneous) \\
\hline SK106/H.cumingii & orange -slight grey up/down (inhomogeneous) \\
\hline SK116/H.shlegelii & light yellow (homogeneous) \\
\hline SK117/H.shlegelii & white (homogeneous) \\
\hline SK118/H.shlegelii & light pink (homogenous) \\
\hline SK119/H.shlegelii & light pink (homogenous) \\
\hline SK120/H.shlegelii & light grey (homogeneous) \\
\hline
\end{tabular}

Figures 2 to 6 show comparative Raman spectra natural- and treated-color FWCPs of similar color. The upper spectra are that of the treated sample and at the bottom that of the natural-color pearl. Observing the spectra, all of our naturally colored FWCPs present show two intense additional bands in the $1000-1600 \mathrm{~cm}^{-1}$ region. Some slight changes in shape and relative intensities of the two more intense bands are visible from one natural colored sample to the next. 
This is due to a different mixture of polyenic pigments (Karampelas et al. 2007). Polyenic pigments can also give weak bands at 1010, 1190 and $1295 \mathrm{~cm}^{-1}$ (Fig. 5). Raman spectra recorded over a wider frequency region show the overtone and others previously observed combination bands (Okamoto et al. 1984).

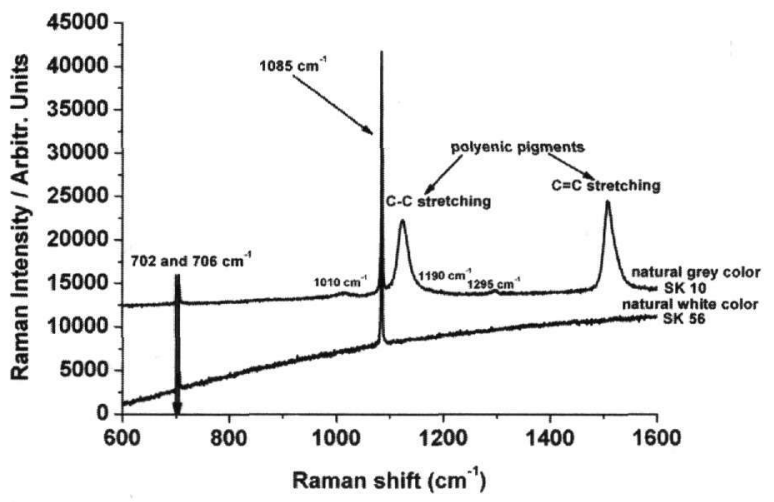

Figure 1 - Raman spectra of a white (SK 56) and a natural grey (SK 10) pearl, under green excitation $(514.53 \mathrm{~nm})$. For the white sample, we observe the aragonite bands at about 1085 $\mathrm{cm}^{-1}$ and at about 702 and $706 \mathrm{~cm}^{-1}$, which correspond respectively to the $v_{1}$ symmetric and

$\mathrm{v}_{4}$ in plane bending mode of the carbonate ion in aragonite. For the grey color pearl, in addition to aragonite bands, we observe two peaks (at about 1130 and $1530 \mathrm{~cm}^{-1}$ ) due to polyenic pigments. Additional weak bands at 1010, 1190 and $1295 \mathrm{~cm}^{-1}$ are observed in this sample, which are due to polyenic pigments also

Table 2 - Description of our samples of treated-color cultured freshwater pearls describing their color range, their homogeneity their treatment if known

\begin{tabular}{|c|c|}
\hline Sample number/Mollusk & Color description and distribution/treatment \\
\hline SK03/unknown & grey (homogeneous) /unknown \\
\hline SK12/H.cumingii & grey (homogeneous) /unknown \\
\hline SK13/H.cumingii & orange (inhomogeneous) /unknown \\
\hline SK14/H.cumingii & orange (inhomogeneous) /unknown \\
\hline SK15/H.cumingii & orange (inhomogeneous) /unknown \\
\hline SK62/unknown & grey (homogeneous) /unknown \\
\hline SK63/unknown & grey (homogeneous) /unknown \\
\hline SK66/unknown & violet-grey (homogeneous)/unknown \\
\hline SK72/unknown & light pink (inhomogeneous) /unknown \\
\hline SK73/unknown & light pink (inhomogeneous) /unknown \\
\hline SK75/unknown & light grey (homogeneous) /unknown \\
\hline SK76/unknown & light yellow (inhomogeneous) /unknown \\
\hline SK77/unknown & light yellow (inhomogeneous) /unknown \\
\hline SK80/unknown & violet-grey (homogeneous)/unknown \\
\hline JPG1/unknown & grey (homogeneous)/silver nitrate \\
\hline
\end{tabular}




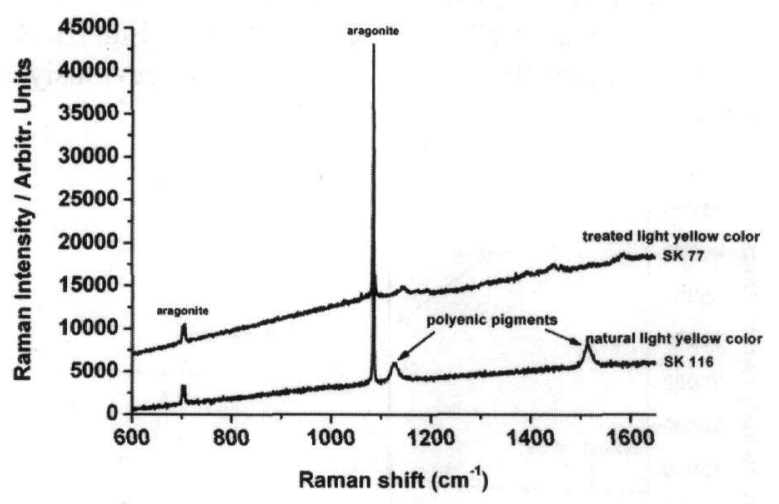

Figure 2 - Raman spectra of a natural light yellow (SK 116) and a treated light yellow (SK 77) pearl, with green excitation (514.53 $\mathrm{nm}$ ). For the natural colored pearl, we observe peaks due to polyenic pigments, absent in the treated-color sample. Moreover, we observe suspicious peaks in the $1100-1600 \mathrm{~cm}^{-1}$ region in the spectrum of the treated-color sample

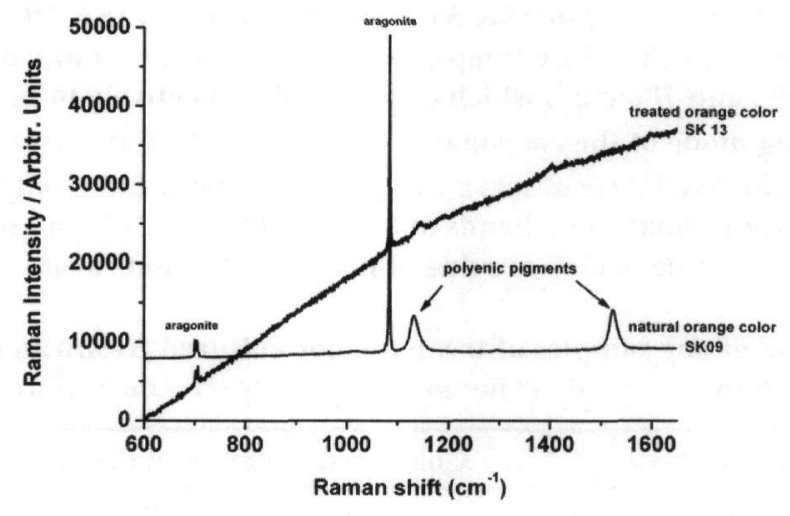

Figure 3 - Raman spectra of a natural orange (SK 09) and a treated orange (SK 13) pearl, with green excitation $(514.53 \mathrm{~nm})$. For the natural-color pearl, we observe peaks due to polyenic pigments, absent in the treated-color sample. Moreover, we observe suspicious peaks in the 1100-1600 cm-1 region in the spectrum of the treated-color plus an additional strong luminescence

In figures 2 and 3 we observe that the treated light yellow and orange colored FWCPs show additional Raman peaks in the region of $1100-1600 \mathrm{~cm}^{-1}$, which are not due to polyenic pigments. These are probably characteristic of the organic pigment, used to give these colors.

In figures 4, in the spectrum of pearl SK12 (fig. 5) as well as the spectrum of pearl SK 80 (Fig. 6) we observe that the treated- light pink, grey and violet grey colored FWCPs respectively show no more than aragonite Raman peaks. Thus, their spectra look like those of white FWCP (see again Fig. 1). It seems that inorganic pigments (which don't give any Raman peak) are used to give these colors.

In figure 5 in spectra of pearl SK63 and of SK03 we observe that the treated grey FWCPs present broad Raman bands at about 1330 and $1600 \mathrm{~cm}^{-1}$. These bands may be characteristic of nanocrystallised carbon (due to a decomposition of the organic matter of the pearl during the addition of the pigment) or to silver which is used during the treatment. 


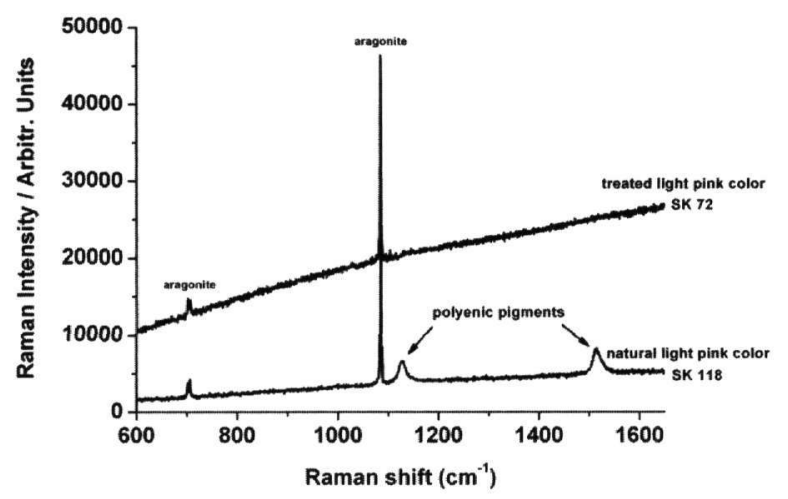

Figure 4 - Raman spectra of a natural light pink (SK 116) and a treated light pink (SK 72) pearl, with green excitation $(514.53 \mathrm{~nm})$. For the natural colored pearl, we observe peaks due to polyenic pigments, absent in the treated-color sample. Spectrum of treated-color sample looks like the spectrum of a white colored pearl (see Fig. 1)

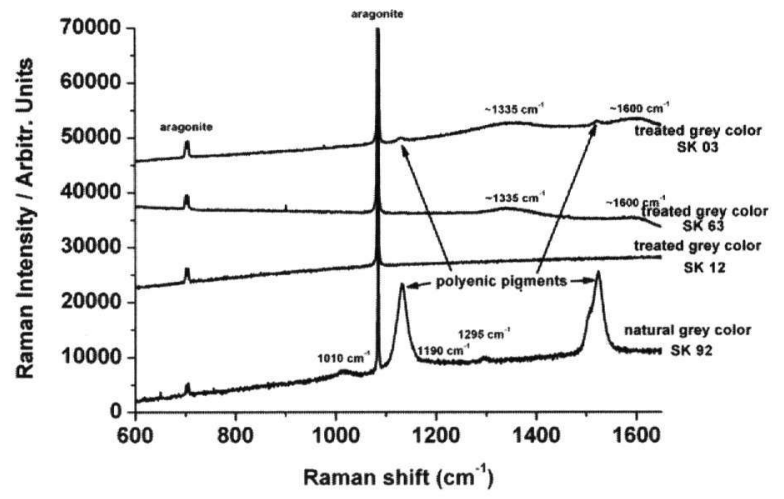

Figure 5 - Raman spectra of a natural grey (SK 92) and three treated light grey (SK 12, SK 63 and SK 03) pearls, with green excitation $(514.53 \mathrm{~nm})$. For the natural colored pearl, we observe peaks due to polyenic pigments, absent in the treated-color samples SK 12 and SK63. Additional weak bands at 1010,1190 and $1295 \mathrm{~cm}^{-1}$ are observed in the natural-color sample, which are due to polyenic pigments also. Spectrum of pearl SK 12 looks like the spectrum of a white colored pearl (see fig. 1). Moreover in the spectra of the samples SK 63 and SK 03, we observe two large additional peaks at about 1335 and $1600 \mathrm{~cm}^{-1}$ due to the treatment. Also, there are barely visible peaks due to polyenic pigments in the treated-color sample SK03

In figure 6 the treated-color violet-grey FWCP SK 80 show small additional Raman peaks which are barely visible -probably due to polyenic pigments present before treatment. In spectrum of pearl SK66 an additional strong luminescence in comparison with the white sample is observed. This is probably due to the pigment added during the color treatment. 


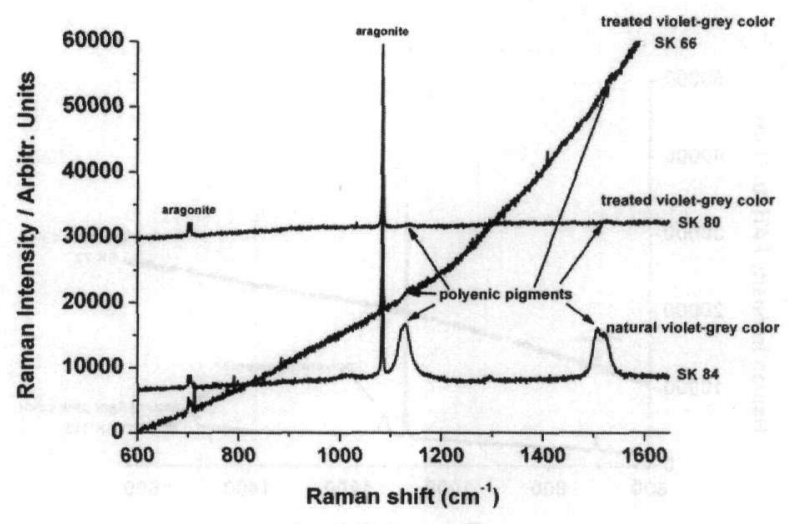

Figure 6 - Raman spectra of a natural violet-grey (SK 84) and two treated violet-grey (SK 80 and SK 66) pearls, with green excitation $(514.53 \mathrm{~nm})$. For the natural colored pearl, we observe peaks due to polyenic pigments. Note the presence of barely visible peaks due to polyenic pigments in the treated-color samples. In sample SK66 there is a strong luminescence, probably due to an artificial pigment

\section{Discussion and conclusion}

All of our natural colored FWCPs contain polyenic pigments, which appear to be the principal cause of their color. Raman scattering, with green excitation, with their characteristic peaks at about $1130( \pm 10)$ and $1530( \pm 25) \mathrm{cm}^{-1}$ identifies these pigments (Karampelas et al. 2007). Weak bands at 1010,1190 and $1295 \mathrm{~cm}^{-1}$ can be also present. We observe also that strong colors present more intense peaks by comparison to lighter colored samples (see spectrum of sample SK 116 in Fig. 2 and of sample SK 116 in Fig. 4).

If a colored cultured pearl is received in a laboratory in order to identify if its color is natural or not, we propose first of all to observe it under a microscope for a possible detection of unusual color concentration in the form of colored layer (visible in the drill hole, if the pearl is drilled) or a color spot or streak visible on the surface. If nothing is observed, we propose to follow with EDXRF measurements. Fresh- or salt- water origin can be identified in this way. Moreover, if an element such as silver, iodine or bromine is detected, it means that the pearl is of artificial color. However, if nothing suspicious is detected with this method and the pearl is from freshwater, Raman scattering is a useful tool. The absence of characteristic polyenic bands at about $1130( \pm 10)$ and $1530( \pm 25) \mathrm{cm}^{-1}$ in a colored FWCP means that its color is artificial (see Figs 4 -pearl SK 72-, and 5 -pearl SK12-). Moreover, if peaks due to polyacetylenic compounds are detected with other unusual peaks, as in the case of pearl SK 03 (see Fig. 5) or with strong luminescence as in the case of pearl SK66 (see Fig. 6), the pearl has a treated color. Additionally, if bands other than polyenic are present in the Raman spectrum (see Figs 2 -SK 77-, and 3 -SK13-), the pearl contains foreign products, and is these probably of artificial color.

The presence of polyenic pigments cannot identify the natural origin of color in a FWCP. This is because in some cases small polyenic bands can be detected in treated-color samples. This is probably because a small quantity of these pigments before the color treatment. Similar weak signals due to polyenic pigments may be also identified in white colored FWCPs. This is due to the fact that these pigments present strong resonant phenomena. Thus, these pigments can be detected in very low concentrations (Hoskins et al. 1977). If color treatment gives Raman peaks, as is the case of SK03 pearl (Fig. 5) or SK 66 (Fig. 6), this is not a problem. However, this is may be a problem in the case of a sample, which contains polyacetylenic pigments before the treatment, 
and the treatment does not add a Raman peak. Our research team is working with UV-Vis-NIR spectroscopy in reflection, and luminescence spectroscopy in order to find a solution to this problem, as well as to the identification of treated-color saltwater pearls.

\section{Acknowledgments}

The authors wish to thank Mr. Alain Boite, Alain Boite Co., Paris, France, for loaning more than half of the pearls studied. Other samples were obtained from the Swiss Gemological Institute SSEF (Schweizerische Stiftung für Edelstein-Forschung) in Basel, from professor J.-P.Gauthier, from Lyon University, LFG (Laboratoire Francais de Gemmologie) in Paris, France, from Luc Genot, from Gemline, Brussels, Belgium and from Mr. Pascal Moine, from Christian Bernard Co., Paris, France, which the authors wish to thanks equally. SK is grateful to the Hellenic General Secretariat for Research and Technology (G.S.R.T.) for financial assistance (PENED 2003) during this project.

\section{References}

Akamatsu, S., Zansheng, T.L., Moses, M.T., and Scarratt, K., 2001. The Current Status of Chinese Freshwater Cultured Pearls, Gems\&Gemology, 37(2), 96-113.

Crowningshield, G.R., 1991. Gem Trade Lab Notes: Green-Dyed Natural Pearls, Gems\&Gemology, 27(3), 175.

Elen, S., 2001. Spectral reflectance and fluorescence characteristics of natural-color and heattreated "golden" south sea cultured pearls, Gems\&Gemology, 37(2), 114-123.

Elen, S., 2002. Note\&New Techniques: Update on the identification of treated "golden" south sea cultured pearls, Gems\&Gemology, 38(2), 156-159.

Fengming, H., Xinqiang, Y., Mingxing, Y., and Zhonghui, C., 2003. Pearl cultivation in Donggou, Ezhou, Hubei, and cathodoluminescence of cultured pearls, Journal of Gemmology, 28(3), 449-462.

Fryer, C., 1984. Gem Trade Lab Notes: First American Freshwater Cultured Pearls from Tennessee, Gems\&Gemology, 20(4), 229-230.

Gauthier, J-P., and Lasnier, B., 1990. La perle noire obtenue par traitment a l'argent, Revue de Gemmologie, A.F.G., 103(1), 3-6.

Goebel, M., and Dirlam, D.M., 1989. Polynesian black pearls, Gems\&Gemology, 25(3), 130-148.

Gütmannsbauer, W., and Hanni, H.A., 1994. Structural and chemical investigations on shell and pearls of nacre forming salt- and freshwater bivalve mollusks, Journal of Gemmology, 24(4), 241-252.

Hänni, H.A., 1999. Sur la formation de nacre et de perles, Revue de Gemmologie, A.F.G., 137(1), 30-36.

Hargett, D., 1987. Gem Trade Lab Notes: Black Cultured Pearls, Gems\&Gemology, 23(3), 166.

Hoskins, C., and Alexander, V., 1977. Determination of carotenoid concentrations in marine phytoplankton by resonance Raman spectrometry, Analytical Chemistry, 49(6), 695-697.

Hurwit, K., 1984. Gem Trade Lab Notes: Dyed Cultured Pearls, Gems\&Gemology, 20(4), 229.

Jobbins, E.A., and Scarratt, K., 1990. Some aspects of pearl production with particular reference to cultivation at Yangxin, China, Journal of Gemmology, 22 (1), 3-15.

Kane, R., 1990. Freshwater Natural, Gems\&Gemology, 26 (3), 223-224. 
Karampelas, S., Fritsch, E., Mevellec, J.-Y., Gauthier, J.-P., Sklavounos, S., and Soldatos, T., 2007. Determination by Raman scattering of the nature of pigments in cultured freshwater pearls from the mollusk Hyriopsis cumingii, Journal of Raman Spectroscopy, 38 (3), pp.217-230.

Kennedy, S.J., 1998. Pearl identification, Australian Gemmologist, 20 (1), 2-19.

Kiefert, L., Moreno, D.M., Arizmendi, E., Hänni, H., and Elen, S., 2004. Cultured pearls from the Gulf of California, Mexico, Gems\&Gemology, 40(1), 26-38.

Komatsu, H., 1999. The identification of pearls in Japan. - A status quo summary, Journal of the Gemmological Society of Japan, 20(1-4), 111-119.

Li, L., and Chen, Z., 2001. Cultured pearls and colour-changed cultured pearls: Raman spectra, Journal of Gemmology, 27(8), 449-455.

Matsuda, Y., and Miyoshi, T., 1988. Effects of [gamma]-ray irradiation on colour and fluorescence of pearls, Japanese Journal of Applied Physics, 27(2), 235-239.

Okamoto, H., Saito, S., Tasumi, M.., and Eugster, C., 1984. Resonance Raman spectra and excitation profiles of tetradesmethyl- $\beta$-Carotene, Journal of Raman Spectroscopy, 15(5), 331-335.

Salares, V.R., Young, N.M., Carey, P.R., and Bernstein, H.J., 1977. Excited state (excitation) interactions in polyene aggregates. Resonance Raman and absorption spectroscopic evidence, Journal of Raman Spectroscopy, 6(6), 282-288.

Scarratt, K., Moses, T., and Akamatsu, S., 2000. Characteristics of nuclei in Chinese freshwater cultured pearls, Gems\&Gemology, 36(2), 98-109.

Schoeffel, H., 1996. Pearls. From the myths to modern pearl culture, Schoeffel Pearl Culture, Stuttgart, 119pp.

Sweaney, J.L., and Latendresse, J.R., 1984. Freshwater pearls of North America, Gems\&Gemology, 20(3), 125-140.

Vock, A., 1997. Disclosure needed for a healthy industry, Jewellery News Asia, 158(10), 52-54. 